\title{
Comparison of Leukocyte, Neutrophil, and Lymphocyte Levels in Child Patients that Experienced Breathlessness with COVID-19 and Non-COVID-19 (2020-2021) in Medan, Indonesia
}

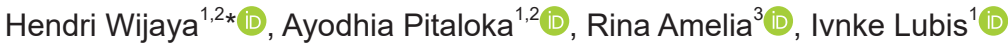 \\ ${ }^{1}$ Department of Pediatrics, Faculty of Medicine, Universitas Sumatera Utara, Medan, North Sumatera, Indonesia; ${ }^{2}$ Adam Malik \\ General Hospital, Medan, North Sumatera, Indonesia; ${ }^{3}$ Department of Community Medicine and Public Health, Faculty of \\ Medicine, Universitas Sumatera Utara, Medan, North Sumatera, Indonesia
}

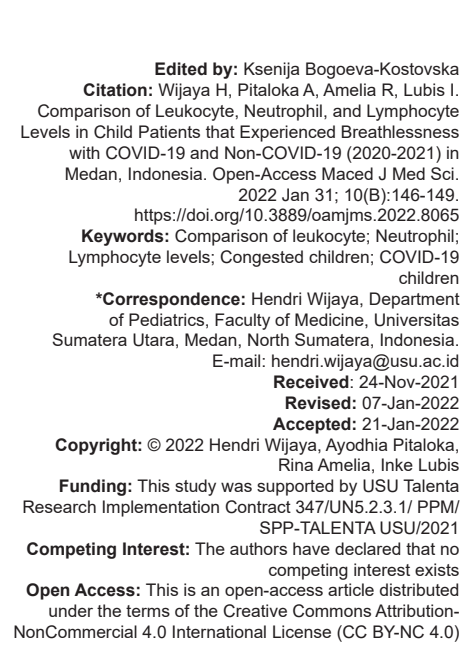

\section{Introduction}

COVID-19 is a zoonotic disease caused by severe acute respiratory syndrome coronavirus 2 (SARS-CoV-2) [1]. Transmission of COVID-19 from person to person occurs through the spread of droplets when an infected person coughs or sneezes [2]. Various risk factors affect the morbidity and mortality of COVID-19, such as age, gender, ethnicity, comorbid conditions, and laboratory parameters. Individuals who are older and with comorbid conditions have a higher risk of COVID-19 mortality. However, younger individuals without underlying disease may also develop fatal complications such as myocarditis and the development of disseminated intravascular coagulopathy [3]. COVID-19 from person to person occurs through the spread of droplets when an infected person coughs or sneezes [2]. In a study in seven countries, namely, the United States, Britain, Italy, Germany, Spain, France, and South Korea, the child mortality rate due to COVID-19 until February 2021 was still rare at 0.71/100,000 population [4].

The clinical manifestations of COVID-19 in children are asymptomatic mild degrees or with acute upper respiratory tract symptoms and moderate degrees with clinical pneumonia [5]. In general, the symptoms of COVID-19 in children are mild and can be treated at home. However, children with moderate or severe symptoms require hospitalization for observation and supportive care [6]. COVID-19 is a systemic infection with a significant impact on the hematopoietic system and hemostasis [7]. In the course of the COVID-19 pandemic, several biomarkers are needed that can be 
useful in risk stratification to predict the severity and fatality of COVID-19. Several biomarkers are used as markers of disease progression to a critical degree, such as leukocytes, lymphocytes, platelets, interleukin (IL)-6, and serum ferritin [8].

An increase in leukocytes and neutrophils and a decrease in lymphocytes are associated with the severity and mortality of COVID-19 [8]. Lymphopenia can be considered a cardinal laboratory finding with prognostic potential. Neutrophil/lymphocyte ratio and platelet/lymphocyte ratio can be of prognostic value in determining severe cases of COVID-19 [7]. Laboratory findings in children with COVID-19 include decreased lymphocytes, leukopenia, and increased procalcitonin [5]. In severe COVID-19, children often have abnormal laboratory parameters that suggest a systemic inflammatory response. Severe COVID-19 is often complicated by leukopenia, lymphopenia, thrombocytopenia, and coagulopathy, leading to disseminated intravascular coagulopathy [7]. Therefore, in this study, routine blood tests were carried out, including the levels of leukocytes, neutrophils, and lymphocytes in children with COVID-19 and non-COVID-19. This study aims to compare the levels of leukocytes, neutrophils, and lymphocytes in children who are congested with COVID-19 and non-COVID-19 sufferers.

\section{Materials and Methods}

This study is an analytic study with a crosssectional approach to pediatric patients who were treated in Haji Adam Malik Hospital Medan with the complaints of shortness of breath. Patient data were assessed based on the characteristic values of hemoglobin, leukocytes, neutrophils, lymphocytes, and COVID-19 polymerase chain reaction (PCR) results, and then, statistical analysis was performed using SPSS software on a computer. The pediatric patient was then checked for COVID-19 status using a PCR swab, and then, routine blood tests were carried out. The study samples were 276 patients, with 43 confirmed positive COVID-19 patients and the remaining 233 negative patients. The source of this research data is from the patient's medical record for 1 year (2020-2021).

Univariate analysis was performed to obtain the distribution of sample characteristics. Categorical data will be displayed as frequency and percentage, while numerical data as mean and standard deviation if normally distributed or as median and minimum and maximum values if data are not normally distributed. The data on the characteristics of the patients were then tested for the normality of the data distribution using the Kolmogorov-Smirnov. Furthermore, the data were analyzed using the independent t-test analysis test if the data were normally distributed $(p<0.05)$ or the Mann-Whitney statistical test was used if the data were not normally distributed $(p<0.05)[9]$.

\section{Results}

All participants who took part in this study were 276 people and were assessed based on characteristics including the values of hemoglobin, leukocytes, neutrophils, lymphocytes, and COVID-19 PCR results. Based on the hemoglobin value, the highest percentage was $40.6 \%$ (112 people) with a hemoglobin value $<12 \mathrm{~g} / \mathrm{dL}$ followed by a hemoglobin value of $15-16 \mathrm{~g} /$ $\mathrm{dL}$ with a percentage of $12.3 \%$ (34 people). Only $3.6 \%$ (10 people) had a hemoglobin value of $17-18 \mathrm{~g} / \mathrm{dL}$. From the leukocyte value, most of the participants had a leukocyte value above $11,000 \mathrm{~L}$, which was $69.2 \%$ (191 people), but only about $5.4 \%$ (15 people) had a leukocyte value $<4000 \mathrm{~L}$. As many as, 60.1\% (166 people) had neutrophil values above $60 \%$ for neutrophil values. The values obtained from the lymphocyte examination were the highest, namely, $43.8 \%$ (121 people) with $<20 \%$ lymphocytes, 38.8\% (107 people) with 20-40\% lymphocytes, and the lowest was $17.4 \%$ (48 people) with $>40 \%$ lymphocytes. From the COVID-19 PCR examination, participants with positive results were $15.6 \%$ (43 people) and $84.4 \%$ (233 people) negative. Patient characteristics are shown in Table 1.

Table 1: Characteristics of patients based on levels of hemoglobin, leukocytes, neutrophils, lymphocytes, and PCR results

\begin{tabular}{lll}
\hline Characteristics & Frequency $(\mathrm{n})$ & Percentage \\
\hline Hemoglobin $(\mathrm{g} / \mathrm{dL})$ & 112 & \\
$<12$ & 32 & 40.6 \\
$12-13$ & 32 & 11.6 \\
$13-14$ & 23 & 11.6 \\
$14-15$ & 34 & 12.3 \\
$15-16$ & 20 & 7.2 \\
$16-17$ & 10 & 3.6 \\
$17-18$ & 13 & 4.7 \\
$>18$ & 15 & 5.4 \\
Leukocytes $(\mu \mathrm{L})$ & 70 & 25.4 \\
$<4.000$ & 191 & 69.2 \\
$4.000-11.000$ & & \\
$>11.000$ & 45 & 16.3 \\
Neutrophils $(\%)$ & 65 & 23.6 \\
$<40$ & 166 & 60.1 \\
$40-60$ & & \\
$>60$ & 121 & 43.8 \\
Lymphocytes $(\%)$ & 107 & 38.8 \\
$\quad<20$ & 48 & 17.4 \\
$20-40$ & & \\
$\quad>40$ & 43 & 84.4 \\
PCR COVID-19 & 233 & \\
Positive & & \\
Negative & &
\end{tabular}

The results of the analysis of descriptive statistical values from the examination of hemoglobin, leukocytes, neutrophils, and lymphocytes are shown in Table 2. From the statistical analysis results, it was found that the average hemoglobin value was $12.43 \pm 3.69 \mathrm{~g} / \mathrm{dL}$ with a median of $12.80 \mathrm{~g} / \mathrm{dL}$. Meanwhile, from the results of leukocyte examination, the average value was $25,695.43$, and the median was 15.59 . The average neutrophil and 
lymphocyte examination value was $59.67 \pm 21.38 \%$ and $26.14 \pm 16.55 \%$, while the median value was 65.50 for neutrophils and 22.15 for lymphocytes. Table 3 showed the results of the analysis using the Mann-Whitney test, it was found that there were differences in the levels of leukocytes, neutrophils, and lymphocytes in children who were congested with COVID-19 and nonCOVID-19 ( $p<0.05)$. However, there was no difference in hemoglobin levels in children who were congested with COVID-19 and non-COVID-19 ( $p>0.05)$.

Table 2: Levels of hemoglobin, leukocytes, neutrophils, and lymphocytes in children who are congested with COVID-19 and non-COVID-19

\begin{tabular}{llllll}
\hline Parameter & Mean & Median & SD & Min & Max \\
\hline Hemoglobin $(\mathrm{g} / \mathrm{dL})$ & 12.43 & 12.80 & 3.69 & 0.30 & 20.0 \\
Leukocytes $(\mu \mathrm{L})$ & $25,695.43$ & 15.59 & 67,864 & 1470 & 743,680 \\
Neutrophils $(\%)$ & 59.67 & 65.50 & 21.38 & 0.70 & 95.0 \\
Lymphocytes $(\%)$ & 26.14 & 22.15 & 16.55 & 0.30 & 91.10 \\
\hline
\end{tabular}

\section{Discusion}

In this cross-sectional study, it was found that there were significant differences between the levels of leukocytes, neutrophils, and lymphocytes in routine blood examinations between pediatric patients complaining of shortness of breath with confirmed COVID-19 and nonCOVID-19 taken in the 2020-2021 period at the HAMGH Medan. The results are consistent with several previous studies. A study by Wagner found that routine blood tests can be used to help diagnose diseases such as acute kidney injury $(\mathrm{AKI})$ with signs such as lymphopenia and help in the prognosis of diseases such as COVID-19 [10]. In a study by Fuad et al. on patients in a Respiratory Intensive Care Unit in a hospital in the city of Banda Aceh from March to September 2020, it was found that COVID-19 patients change in neutrophil and lymphocyte levels can be used to determine the probability of mortality and morbidity. In COVID-19 patients where $16.6 \%$ had high levels of neutrophils and lymphocytes, it was recognized that further research was needed to examine at-risk demographics and COVID-19 19 such as diabetes, hypertension, and obesity to strengthen the findings of this study [11].

For pediatric patients themselves, in a study in 2020, in a study in China, it was found that among 182 pediatric patients in the study, levels of neutrophils, lymphocytes, and leukocytes did not have a significant relationship in COVID-19 when compared with adult patients. In addition, pediatric patients who present with COVID-19 will usually not complain of severe symptoms or may be asymptomatic. Further studies should be conducted with larger sample sizes in which patients with allergies and other respiratory disorders are given more attention [12].

Results from the previous research studies provide deep insight into immunological effects in
Table 3: Comparison of hemoglobin, neutrophil, and lymphocyte levels in congested children with COVID-19 and non-COVID-19

\begin{tabular}{llll}
\hline Variable & non COVID-19 $(\mathrm{n}=233)$ & COVID-19 $(\mathrm{n}=43)$ & $\mathrm{p}$-value \\
\hline $\begin{array}{l}\text { Hemoglobin }(\mathrm{Hb}) \\
\text { (mean; median; SD) }\end{array}$ & $12.5 ; 12.6 ; 3.7$ & $11.9 ; 13.0 ; 3.6$ & 0.269 \\
Leukocytes & $24,298.9 ; 16,820.0 ;$ & $33,263.0 ; 9,640.0 ;$ & $0.0001^{*}$ \\
& $59,008.3$ & $104,096.2$ & \\
Neutrophils & $61.0 ; 67.8 ; 20.9$ & $52.4 ; 55.7 ; 22.6$ & $0.007^{*}$ \\
Lymphocytes & $24.8 ; 20.9 ; 15.5$ & $33.6 ; 32.3 ; 20.1$ & $0.004^{*}$ \\
\hline
\end{tabular}

children with COVID-19. Older children had more changes in lymphocyte subsets, including more cases with increased T-cell and CD8+ T-cell percentages and decreased B-cell counts. Younger children were more likely to be associated with increased cell counts and percentages. Consistent with clinical symptoms and laboratory findings, subsets of lymphocytes and cytokines did not differ in allergic and non-allergic COVID-19 patients. Thus, allergy plays a more significant and often overlooked role in the incidence, course, and outcome of COVID-19 in children [12].

A study conducted in China found no difference between severe and moderate cases in leukocyte count in correlation analysis, and lymphopenia was reported to occur even when the leukocyte count was average. Consistent with the previous studies, lymphopenia was frequently detected even when leukocyte and neutrophil counts were average in the hospital setting for COVID-19 cases. Immune cells infiltrate the lungs and cause severe, unexplained lung infections.

In one study, the lymphocyte count was found to be $<1.0 \times 10^{9} / \mathrm{L}$. The human immune response created by lymphocytes is triggered by a viral infection, whereas systemic infection suppresses cellular immunity. Novel coronavirus can mainly act on lymphocytes, especially T23 lymphocytes. Total lymphocytes, CD4+, T cells, CD8+ $T$ cells, B cells, and NK cells were decreased in COVID19 patients, and severe cases had lower levels of these cells than mild cases. Therefore, when induced by SARSCoV-2 infection, inflammation-associated lymphopenia increases [13]. Studies show that when patients have no exclusive symptoms in the early stages of COVID-19 disease, the peripheral blood leukocyte and lymphocyte counts are normal or slightly reduced. At the same time, these indicators may change as the disease progresses. A study in hospitalized patients diagnosed with COVID19 based on a computed tomography scan showed that the leukocyte count was within normal limits in $68.1 \%$ of patients, increased in $12.3 \%$ of patients, and decreased in $19.6 \%$ of patients. Leukopenia has been reported in other studies as a possible association between the severity of leukopenia and the severity of COVID-19 [14].

According to Zhao et al., COVID-19 cases with increased leukocyte counts showed increased concentrations of procalcitonin, C-reactive protein (CRP), and IL-6 in serum compared to patients with non-increased leukocyte counts. Thus, the study demonstrated that confirmed COVID-19 patients with elevated leukocyte counts had significantly higher rates of 
a systemic inflammatory response, which was at least in part associated with critical illness progression, with high intensive care unit admission rates and high mortality. The study found that the levels of leukocyte and neutrophil count in the blood when counted, serum concentrations of CRP and IL-6 were significantly increased in patients with increased leukocyte counts with underlying chronic disease, compared with patients with elevated leukocyte counts without the chronic disease [15].

Patients with COVID-19 may have normal leukocyte counts or even low or high leukocyte counts. Further research on the relationship between leukocytes and COVID-19 could assist in following the progression of the disease and assist in making decisions about treatment strategies. The possibility of a cytokine storm alone should be avoided, and the use of granulocyte colony-stimulating factor for leukopenia associated with SARS-CoV-2 should be avoided as it may exacerbate conditions with the early development of acute respiratory distress syndrome [16].

\section{Conclusion}

There are significant differences in the levels of leukocytes, neutrophils, and lymphocytes in patients with shortness of breath with COVID-19 and patients complaining of shortness of breath without COVID-19. These results are consistent with several cases and previous studies where the levels of leukocytes, neutrophils, and lymphocytes can be used as a detection tool and a diagnostic and prognostic tool in COVID-19 patients. Further research is needed to determine how to use the measurement of leukocytes, neutrophils, and lymphocytes as a diagnostic tool and to assist in determining the prognosis.

\section{Acknowledgments}

Acknowledgments to the Chancellor, Head of the Research Institute, and the Dean of the Faculty of Medicine, Universitas Sumatera Utara, Indonesia.

\section{References}

1. Gorbalenya AE, Baker SC, Baric RS, de Groot RJ, Drosten C, Gulyaeva AA, et al. The species Severe acute respiratory syndrome-related coronavirus: Classifying 2019-nCoV and naming it SARS-CoV-2. Nat Microbiol. 2020;5:536. https://doi. org/10.1038/s41564-020-0695-z
2. Rothan HA, Byraredy SN. The epidemiology and pathogenesis of coronavirus disease (COVID-19) outbreak. J Autoimmun. 2020;109:102433. https://doi.org/10.1016/j. jaut.2020.102433

PMid:32113704

3. Gandhi RT, Lynch JB, Delrio C. Mild or moderate COVID-19. N Engl J Med. 2020;383(18):1757-66. https://doi.org/10.1056/ NEJMcp2009249

PMid:32329974

4. Bhopal SS, Bagaria J, Olabi, B, Bhopal R. Children and young people remain at low risk of COVID-19 mortality. Lancet. 2021;5(5):e12-3. https://doi.org/10.1016/S2352-4642(21)00066-3 PMid:33713603

5. Qiu H, Wu J, Hong L, Luo $Y$, Song Q, Chen D. Clinical and epidemiological features of 36 children with coronavirus disease 2019 (COVID-19) in Zhejiang, China: An observational cohort study. Lancet Infect Dis. 2020;20(6):30198. https://doi. org/10.1016/S1473-3099(20)30198-5

6. She J, Liu L, Liu W. COVID-19 epidemic: Disease characteristics in children. J Med Virol. 2020;92(7):747-54. https://doi. org/10.1002/jmv.25807

PMid:32232980

7. Terpos E, Ntanasis-Stathopoulos I, Elalamy I, Kastritis E, Sergentanis TN, Politou M, et al. Hematological findings and complications of COVID-19. Am J Hemato. 2020;95(7):834-47. https://doi.org/10.1002/ajh.25829

PMid:32282949

8. Henry BM, Deoliveira MHS, Benoit S, Plebani M, Lippi G. Hematologic, biochemical and immune biomarker abnormalities associated with severe illness and mortality in coronavirus disease 2019 (COVID-19): A meta-analysis. Clin Chem Lab Med. 2020;58(7):1021-8. https://doi.org/10.1515/ cclm-2020-0369

PMid:32286245

9. Sastroasmoro S, Ismael S. Dasar-Dasar Metodologi Penelitian Klinis. Jakarta: Sagung Seto; 2016.

10. Wagner J, DuPont A, Larson S, Cash B, Farooq A. Absolute lymphocyte count is a prognostic marker in Covid-19: A retrospective cohort review. Int J Lab Hematol. 2020;42(6):761-5. https://doi.org/10.1111/ijlh.13288 PMid:32779838

11. Fuad M, Oehadian A, Prihatni D. Neutrophil-to-lymphocyte ratio and Covid-19 symptom-based severity at admission. Althea Med J. 2021;8(1):1-6.

12. Du $\mathrm{H}$, Dong $\mathrm{X}$, Zhang JJ, Cao $\mathrm{YY}$, Akdis $\mathrm{M}$, Huang $\mathrm{PQ}$, et al Clinical characteristics of 182 pediatric COVID-19 patients with different severities and allergic status. Allergy. 2021;76(2):510-32. https://doi.org/10.1111/all.14452

PMid:32524611

13. Nalbant, Ahmet KT. Can the neutrophil/lymphocyte ratio (NLR) have a role in the diagnosis of coronavirus 2019 disease (COVID-19)? Rev Assoc Med Bras (1992). 2020;90(264):746-51. https://doi.org/10.1590/1806-9282.66.6.746 PMid:32696861

14. Shahri MK, Niazkar HR. COVID-19 and hematology findings based on the current evidences: A puzzle with many missing pieces. Int $\mathrm{J}$ Lab Hematol. 2021;43(2):160-8. https://doi.org/10.1111/ijlh.13412 PMid:33264492

15. Zhao K, Li R, Wu X, Zhao Y, Wang T, Zheng Z, et al. Clinical features in 52 patients with COVID-19 who have increased leukocyte count: A retrospective analysis. Eur J Clin Microbiol Infect Dis. 2020;39(12):2279-87. https://doi.org/10.1007/s10096-020-03976-8 PMid:32651736

16. Selim S. Leukocyte count in COVID-19: An important consideration. Egypt J Bronchol. 2020;8(1):4-5. 